\title{
Retórica dos títulos em reportagens impressas
}

Ivo José Dittrich

Professor adjunto do Centro de Educação e Letras (UNIOESTE) - Campus de Foz do Iguaçu. E-mail: dtrch@unioeste.br

Dois objetivos centrais orientam a elaboração dos títulos em reportagens impressas: um argumentativo, antecipando o ângulo de abordagem do assunto em pauta; outro persuasivo, despertando a atenção do leitor. Compreender os títulos nessa perspectiva é um caminho para quem os produz e, mais ainda, para quem os lê.

Mesmo o discurso jornalístico - informativo por natureza - objetiva a persuasão. Nem poderia ser diferente: todo comunicador visa, em última análise, a que seu interlocutor acredite nas informações transmitidas e, pelo menos, considere as opiniões expressas. Tem de dar, minimamente, a impressão de que esteja representando, o mais fielmente possível, determinada realidade. Procura assim angariar, manter ou ampliar a confiança do leitor na instituição jornalística. Sabe que ela, por vezes mais que a escola, presta-lhe informações e fornece parâmetros para orientar sua micro e macrovisão.

Nesse universo, a reportagem ocupa posição particular. Em termos aristotélicos ${ }^{1}$, inscreve-se, simultaneamente, nos três gêneros do discurso: é deliberativa porque, além de informar, discute os assuntos para que o leitor delibere com conhecimento de causa; é demonstrativa porque, pelo menos implicitamente, dispõe-se a elogiar ou censurar diferentes autoridades, instituições ou programas; por fim, é judiciária porque, ainda mais implicitamente, predispõe-se a defender determinada causa, quando não se dá o direito de exercer o papel de juiz, condenando ou absolvendo. Todavia, pelo menos por princípio, predomina a primeira. E é nessa ordem de raciocínio que será encarada neste artigo.

Interpretar e informar pressupõe interação positiva com o leitor: além de precisa, a reportagem deve ser agradável, leve e de fácil compreensão. Isso implica admitir que sua linguagem orienta-se tanto pela argumentação quanto pela expressividade. Escolhe os argumentos mais adequados para encaminhar determinada linha de raciocínio, amparada em provas factuais ou de presun-

1. ARISTÓTELES. Arte retórica e arte poética. 14. ed. Rio de Janeiro: Ediouro, s/d. p. 39

2. PERELMAN, C. Tratado da argumentação. São Paulo: Martins Fontes, 1999. p. $75-83$. ção $^{2}$, e, ao mesmo tempo, impressiona (seduz) o leitor por meio de palavras, sintagmas ou enunciados que toquem sua sensibilidade. Desenvolve o raciocínio objetivo (lógos) e busca conquistar sua simpatia (páthos).

Assim, a reportagem apresenta-se como gênero jornalístico com características próprias: "A noção de gênero é, efetivamente, inseparável daquela de estilo. A cada gênero correspondem modos de expressão necessários e rigorosamente 
definidos, que determinam não somente a composição, como também o vocabulário, a sintaxe, as figuras e os ornamentos"3. Torna-se imperativo, portanto, distinguir entre a reportagem impressa e a veiculada pelos meios audiovisuais, principalmente se a retórica do discurso for considerada como sua organização para argumentar e impressionar. Mesmo que os recursos tecnológicos atuais não mais permitam dizer que verba volant scripta manent [as palavras voam, os escritos permanecem], os recursos de que a reportagem impressa dispõe para seduzir e persuadir, se não mais limitados, pelo menos não são os mesmos da reportagem televisiva ou da radiofônica. Nessa lógica, os títulos desempenham papel relevante. Por isso, a delimitação desse artigo à abordagem do seu papel retórico em reportagens impressas, particularmente das que aparecem em revistas semanais de informação geral: Veja, Época, IstoÉ e, mais recentemente, Carta Capital.

\section{CARÁTER PUBLICITÁRIO DOS TÍTULOS}

Pode parecer estranho (ou óbvio) encarar os títulos de reportagens sob esse prisma. Sem entrar no mérito de qualquer distinção teórica entre publicidade e propaganda, observa-se que o título funciona como vitrine do texto: além de ajudar a vender a revista, no sentido comercial do termo, vende a reportagem, isto é, incita assinantes e compradores à leitura.

De acordo com Carvalho ${ }^{4}$, a publicidade utiliza vários recursos para influenciar o destinatário: a) ordenando - fazendo agir; b) persuadindo - fazendo crer; c) seduzindo - buscando prazer. Não parece exagero supor que os títulos de reportagens também cumpram essa função persuasiva, embora de forma velada: são elaborados para que o público leia a reportagem, acredite nela e sinta prazer ao fazê-lo.

Parece possível, então, identificar recursos lingüísticos e estilísticos utilizados na mídia impressa para persuadir e seduzir o leitor. O título é um deles: condensa um ponto de vista - argumenta - e, ao mesmo tempo, seduz o leitor, convocando-o para a leitura da reportagem. Pode-se dizer que, pelo menos nesse gênero jornalístico, a titulação segue a evolução do próprio discurso publicitário: substituiu a objetividade informativa pela linguagem sedutora e persuasiva. Com a qualidade das fotografias - há repórteres fotográficos e não apenas fotógrafos - e com os recursos de diagramação pode-se dizer que, tal como a mensagem publicitária, o título constitui-se numa estrutura icônico-lingüística, principalmente quando se trata da reportagem de capa. Observe-se, por exemplo, a da revista Veja ${ }^{5}$ : em caixa alta, a expressão A face da derrota encontra-se sobreposta à figura de um soldado da guarda republicana do Iraque, com o capacete de plástico preso à cabeça com tiras de pano. No sentido dessas palavras, aliado à imagem, transparece a perspectiva da revista: o Iraque já perdeu. Dificilmente o leitor deixaria de inferir esse significado. Todavia, por mais interessante que seja abordar os títulos nessa perspectiva ampla (semiótica), este artigo limita-se à análise dos recursos de ordem lingüística.

3. GUIRAUD, P. A estilística. São Paulo: Mestre Jou, 1970. p. 25.

4. CARVAlHo, N. Publicidade: a linguagem da sedução. 3. ed. São Paulo: Ática, 2002. p. 10.

5. VEJA. São Paulo: Abril, n. $1.797,9$ abr. 2003. 
comunicação \& educação • Ano XI • Número 1 • jan/abr 2006

\section{NATUREZA PERSUASIVA E EXPRESSIVA DOS TÍTULOS}

Os títulos exploram a característica simultaneamente expressiva e argumentativa das expressões lingüísticas, sejam elas verbais ou nominais: procuram impressionar o leitor a ponto de estimulá-lo a se interessar pelo conteúdo da reportagem e, ao mesmo tempo, contribuem com o texto no sentido de condensar sua perspectiva (subjacente ou explícita) em relação ao assunto abordado. Tal como o produto anunciado pela publicidade, não podem enganar o consumidor sob pena de perder a credibilidade. Só podem, portanto, de forma atraente, enunciar o que o texto efetivamente aborda. Paradoxalmente, de forma clara e objetiva, devem ser capazes de prender a atenção do leitor e levá-lo ao texto. Sua elaboração exige, além do conhecimento lingüístico, uma boa dose de criatividade. "A titulação da notícia é uma arte. Mesmo profissionais de imprensa competentes nem sempre conseguem produzir títulos atraentes, embora redijam textos de excelente qualidade"6.

Para conquistar a simpatia do seu leitor, as expressões lingüísticas orientamse, também, pela natureza do páthos, não no sentido de patético ou patológico, mas no de paixão. Promovem a empatia entre a instituição jornalística e seu público consumidor: quanto mais positiva a interação entre ambos, mais provável a fidelidade de quem consome o produto. Ressalte-se que a paixão, pelo seu vínculo com o sensível, não deixa de ser razoável: desperta um exercício de imaginação, de raciocínio, de possível antecipação sobre o provável conteúdo e enfoque a ser perseguido pelo texto. Ao mesmo tempo, as expressões lingüísticas dos títulos vinculam-se ao lógos, no sentido de encaminhar, objetivamente, os argumentos que sustentam a perspectiva privilegiada pela reportagem. É seu caráter racional, em que os sentidos são associados com o provável conhecimento prévio dos seus virtuais leitores. Pode-se dizer, portanto, que o título apresenta, ao mesmo tempo, caráter razoável e racional ${ }^{7}$. Ao lado da paixão e da racionalidade, pode-se acrescentar que, em termos retóricos, a titulação também representa o éthos da instituição jornalística: sua ética não permite enunciar (ou anunciar) mais do que o texto comporta; a credibilidade depende disso.

6. LUSTOSA, E. O texto

da notícia. Brasília: Editora da UnB, 1996. p. 150.

7. PARRET, H. A estética da comunicação: além da pragmática. Tradução de Roberta P. de Oliveira. Campinas, SP: Unicamp, 1997.

8. CARVALHO, N., op. cit., p. 36.

9. DITTRICH, I.; LAGE, N. Ideologia e marketing: o espaço da opinião nas editorias econômicas dos magazines semanais de informação. Revista Brasileira de Ciências da Comunicação, v. XXV, n. 2, p. 97, jul./dez. 2002.

\section{CATEGORIA DAS PALAVRAS NOS TÍTULOS}

Desde a tradição grega, as palavras costumam ser classificadas em duas grandes categorias: as de sentido lexical - substantivos, adjetivos, verbos e alguns advérbios - relacionam a linguagem à realidade; as de sentido gramatical - artigos, preposições, conjunções - assinalam as relações sintáticas, organizam o enunciado. As primeiras "são palavras com forte componente semântico, que se enriquecem continuamente, acompanhando o dinamismo do mundo" ". Trata-se de um conjunto aberto e dinâmico, portanto. Como o veículo de comunicação quer se manter atualizado, seguindo as tendências da moda lingüística, tais palavras refletem, por um lado, aspectos socioculturais em evidência e, por outro, desencadeiam expressões nominais ${ }^{9}$ ou verbais que, virtualmente, a língua torna possíveis. É de supor, portanto, que essa categoria de palavras será preponde- 
rante na constituição dos títulos, desempenhando o papel da racionalidade, da estética e da ética do texto impresso.

De acordo com o Manual de estilo da Editora Abril, "O título é a chave. Para funcionar, precisa ter impacto. Sem impacto, não chamará atenção. Se não chamar a atenção, será inútil" ${ }^{\prime 10}$. Na seqüência, arremata a abordagem dizendo que os melhores títulos têm curtas e poucas palavras. Para além do aspecto racional e objetivo, a criação de um título com essas características apóia-se na intuição. Além de amplo conhecimento sobre as possibilidades de criação lingüística, contam muito a vivacidade, a atualidade e a capacidade intuitiva para sacar o que impressiona e seduz o leitor. É o caso de títulos como Fim de reinado ${ }^{11}$ ou Colcha de retalhos ${ }^{12}$. Num e noutro, o exagero cria impacto e incita o leitor a descobrir do que se trata.

Teoricamente, entretanto, não parece fácil dizer como e por que determinadas palavras ou construções geram maior ou menor impacto, isto é, têm mais poder de atração sobre o público leitor. A estética da comunicação ${ }^{13}$, todavia, pode contribuir nesse sentido, uma vez que a elaboração de um título parece exigir que se saiba lidar não apenas com o belo e o agradável, mas também com o surpreendente. $\mathrm{O}$ conceito de razoabilidade - como aspecto racional subjacente à ordem estética - ajuda a compreender o funcionamento da razão que orienta a produção e a contemplação do agradável, do belo e mesmo do sublime. Pode-se dizer que se o belo deixa o observador admirado, o sublime deixa-o estupefato. "Se a figura tem função expressiva e comunicativa é porque insere as paixões num dispositivo 'razoável', numa economia na qual o páthos torna-se comunicável"14.

Essa razoabilidade estética é comandada por processos que se racionalizam pelo fato de o ser humano viver em comunidade e ali exercer seu papel de comunicador. As construções lingüísticas que circulam e gozam de maior ou menor prestígio são captadas e compartilhadas dentro de uma certa ordem ou hierarquia. Há um certo consenso em valorizar e, portanto, avaliar o prazer, a agradabilidade, a beleza ou o impacto que determinadas formas (lingüísticas em nosso caso) são capazes de gerar. A sensibilidade, mesmo individualizada, apóia-se em circunstâncias sociais.

O sensus comunis é constituído por uma tensão entre o sensível e o social - essa tensão tem uma dupla direcionalidade e resolve-se por um duplo movimento: a socialização do sensível e a sensibilização do social ${ }^{15}$.

Um título como $\mathrm{O}$ operário no poder ${ }^{16}$ é mais atraente (ou imponente) que, por exemplo, Lula na presidência: conta com as circunstâncias socio-históricas em que se admite, implicitamente, que o fato de um operário ocupar o cargo máximo do país, além de surpreendente, sensibiliza os brasileiros - uns por serem contra e outros, a favor.

Pode-se dizer, portanto, que na intersubjetividade se processam os sentidos - de maior ou menor impacto no imaginário - de certas expressões lingüísticas. Há esse senso comum, não representável objetivamente, que permite sua interpretação: "A condição da necessidade que um juízo de gosto pretende é a idéia de um sentido comum"17. É através desse juízo de natureza estética que se constitui a compreensão do belo (e do surpreendente) de uma forma mais ou menos consensual. Pelo fato de viver numa comunidade que exercita a ati-
10. EDITORA ABRIL. Manual de estilo. 15. ed. Rio de Janeiro: Nova Fronteira, 1990, p. 22.

11. ISTOÉ. São Paulo: Ed. Três, n. 1.750, p. 82,16 abr. 2003.

12. Ibid., p. 92.

13. PARRET, H., op. cit., p. 111.

14. Ibid., p. 111.

15. Ibid., p. 198.

16. CARTA CAPITAL. São Paulo: Ed. Confiança, $n$. 236, p. 26, 16 abr. 2003.

17. KANT, I. Crítica da faculdade do juízo. Tradução de V. Rohden e A. Marques. 2. ed. Rio de Janeiro: Forense Universitária, 1995. p. 83. 
vidade lingüística, a interpretação é processada a partir de parâmetros estéticos compartilhados. O autor do título Monumento de elegância ${ }^{18}$ certamente conta com o imaginário popular (consensual) sobre que objeto pode ser considerado monumento e quais requisitos caracterizam a elegância.

Não se poderia, portanto, abordar retoricamente o discurso jornalístico apenas em seus aspectos de compreensão objetiva - a racionalidade do lógos. $\mathrm{Na}$ medida em que seus leitores pertencem a uma comunidade discursiva que tem valores (estéticos) em comum (mesmo que não explicitamente estabelecidos), a retórica do texto jornalístico ampara-se na simultaneidade entre a razão racional e a razão razoável. Para além da semântica, o potencial de sedução dos títulos apóia-se na simpatia (páthos) e no gosto (estético) evocados pela sua estrutura e pelo sentido de suas expressões.

Além disso, o raciocínio por abdução também parece guiar a interpretação dos títulos. Com maior ou menor grau de consciência, o leitor busca pistas a partir dos sentidos das palavras e mesmo do material icônico que, normalmente, as acompanha. Ainda segundo Parret, a inferência abdutiva é constituída de duas propriedades: um fato surpreendente e um sistema de antecipações: "As rupturas e as surpresas pedem que as esclareçamos mediante hipótese: elas se definem em relação às nossas antecipações" ${ }^{\prime 1}$.

A versão do fato desenvolvida ao longo da reportagem pode até não ser tão surpreendente, mas a construção do título pretende sê-lo. Pode-se dizer que a sensação de surpresa vincula-se mais propriamente à forma da expressão; seu conteúdo cria um sistema de antecipações: a partir dos sentidos evocados pelo título, o leitor antecipa a possível versão desenvolvida. Parece ser esse o processo inferencial que o autor do texto explora para conseguir seu objetivo: além de apelar para o lado emocional do leitor, pretende forçá-lo a raciocinar por antecipação. Consegue, assim, a disposição do leitor para, pelo menos, iniciar a leitura. É o que ocorre com $\mathrm{O}$ mundo dos falcões ${ }^{20}$, título de uma reportagem que aborda a expansão da política militar americana.

Os subtítulos, por sua vez, manifestam de forma mais clara a perspectiva adotada e, normalmente, apresentam-se como uma espécie de tese. Complementam o título, mas caracterizam-se pela presença de expressões ligadas ao mundo do lógos, predominando a racionalidade. A natureza retórica de suas expressões lingüísticas objetiva contribuir para a persuasão em termos de argumentação racional: das palavras que os compõem derivam sentidos mais previsíveis e, na medida do possível, em menor número. Pode-se dizer que predomina o sentido literal. O subtítulo previne possíveis inferências não condizentes com o teor da reportagem; fornece a pista interpretativa mais confiável.

Paradoxalmente pode, no entanto, contribuir para que o leitor não continue a se interessar pelo texto, principalmente quando for iniciante ou não estiver familiarizado com o assunto. Seria o caso, por exemplo, do título Fogo cruzado $^{21}$ : ele pode despertar, aguçar e atrair a atenção do leitor ao sugerir diversas inferências - é esta a sua finalidade. Todavia, o subtítulo, Engajada, mídia americana perde espaço para as novas redes do Golfo Pérsico, ao definir o teor da reportagem, pode frustrar as expectativas do leitor inexperiente. Ressalte-se, 
entretanto, que a citada reportagem inclui-se entre as que compõem uma seção dedicada à Guerra no Iraque, anunciada a partir da chamada de capa - O atoleiro de Bush - que, pelo menos em tese, deveria contribuir para evitar malentendidos ou inferências dessa ordem. Até que ponto seria (ou não) assim, entretanto, mereceria abordagem mais aprofundada como, aliás, todo estudo da relação entre título e subtítulo.

\section{IMPLICAÇÕES DE ORDEM EDUCACIONAL}

A análise retórica - descrição dos mecanismos racionais e estéticos que promovem a persuasão - pode, de um lado, indicar pistas de titulação para a mídia impressa e, de outro, sugerir encaminhamentos de leitura. Por vezes, o sentido das palavras é menos relevante que a sensibilidade despertada. Com maior ou menor grau de consciência, a escolha das expressões que compõem os títulos indica que a instituição jornalística manipula os sentidos evocados pelas palavras de acordo com a perspectiva adotada na reportagem. Essa manipulação é exercida pela exploração do potencial expressivo que subjaz ao (e está a serviço do) aspecto intelectual (racional) das expressões lingüísticas que compõem o discurso jornalístico, principalmente aquele dos títulos. No afã de impressionar o leitor, a mídia impressa poderia resguardar-se do sensacionalismo que, por vezes, impera nos meios de comunicação de massa. À medida que persuadem o leitor a confiar no enquadramento de determinada realidade, constituem-se em formadoras de opinião, o que implica responsabilidade ética. Os profissionais da educação, por sua vez, deveriam manter-se atentos: é de sua responsabilidade ensinar aos leitores os mecanismos para seduzir pela linguagem, mas também lhes cabe prepará-los para as armadilhas dessa mesma sedução que, por vezes, aparece travestida de argumentação.

Resumo: Este artigo aborda o papel persuasivo e sedutor desempenhado pelo título nas reportagens das revistas de informação geral: a escolha das expressões e da estrutura é orientada pela expectativa de vender não só a revista, mas também a reportagem. Assim, a persuasão é desenvolvida por meio de uma retórica que apóia a racionalidade da argumentação objetiva na sensibilidade da razão estética. Se a conjugação desses aspectos orienta quem escreve, também serve de ponto de partida para quem lê. Na área educacional, o conhecimento dessas estratégias de persuasão pode ajudar a desenvolver uma leitura de melhor qualidade.

Palavras-chave: retórica, persuasão, racionalidade, reportagem.
Abstract: This paper focuses on persuasive and seduction functions performed by the title (heading) on magazine articles: the choice of expressions and its structure is oriented by the expectation for to sell not only the magazine, but also the news. So, persuasion is carried out by a rhetoric that supports the argumentative rationality on aesthetic reasons. These aspects guide not only who writes, but also who reads. In educational area, to know these strategies for persuasion can help to develop a best reading quality.

Keywords: rhetoric, persuasion, rationality, news. 